\title{
Isolated Spinal Cord Arteritis
}

\author{
THOMAS E. FEASBY, GARY G. FERGUSON, AND J. C. E. KAUFMANN
}

SUMMARY: This patient presented as a subacute progressive cervical myelopathy and the differential diagnosis included cervical spondylotic myelopathy and intramedullary mass. Microscopically, vascular lesions plus a patchy myelomalacia indicated a vasculitis. However, there was no suggestion of a generalized vasculitis at autopsy and the only supporting laboratory study was a raised erythrocyte sedimentation rate. It would seem that a vasculitis similar to polyarteritis nodosa or other collagen disease may be confined to the spinal cord.

RÉSUMÉ: Le diagnostic clinique de ce malade était une myélopathie cervicale subaiguë ou une myélopathie cervicale spondylotique ou une tumeur de la moelle épinière. Le diagnostic histologique revèle une myélomalacie focale avec vasculite bien qu'il n'y a pas de vasculite générale. Il semblerait donc q'une vasculite semblable à celles de la polyartérite noueuse et autres maladies du collagène puisse être localisée à la moelle épinière.
From the Departments of Pathology (Neuropathology) and Clinical Neurological Sciences, University Hospital, London, Ontario.

Reprint requests to Dr. J. C. E. Kaufmann, Department of Pathology (Neuropathology), University Hospital, 339 Windermere Road, London, Ontario, Canada N6G $2 \mathrm{~K} 3$.
Spinal cord arteritis occurs infrequently and is usually a manifestation of a systemic vasculitis. This case presented clinically as a subacute cervical myelopathy and proved pathologically to be a vasculitis confined to the cervical spinal cord.

\section{CASE REPORT}

This 57-year-old woman presented with a history of progressive spastic quadriparesis beginning in January 1974. During the three months prior to admission she had noted pain in her neck which radiated to both shoulders and was increased with coughing or sneezing.

There was generalized osteoarthritis, a pronounced dorsal kyphosis, and cervical lordosis. Neurological examination revealed a modest, somewhat asymmetrical, spastic paresis of all limbs, involving the proximal musculature in particular. There was wasting of the intrinsic muscles of both hands. The deep tendon reflexes were brisk, especially in the legs. Plantar reflexes were extensor and the abdominal reflexes were absent. Cranial nerve and sensory examinations were normal. Neck extension produced a shock-like sensation radiating down the spine.

Plain films of the cervical spine revealed moderate spondylosis. The width of the cervical canal was near the lower limit of normal, measuring $15 \mathrm{~mm}$. Cervical myelography demonstrated asymmetrical expansion of the cord from $\mathrm{C} 2$ through $\mathrm{C} 7$ (Figure 1). Routine hematological and biochemical tests were normal. The sedimentation rate was 36 $\mathrm{mm} / \mathrm{hr}$. CSF protein was $38 \mathrm{mg} \%$, glucose, $61 \mathrm{mg} \%$, and there were no cells. The VDRL was negative. The rheumatoid factor was $1 / 20$ (normal).
Certain diagnosis was difficult. The myelogram suggested an intramedullary mass lesion, such as a tumor or syrinx, but the clinical presentation was more in keeping with spondylotic myelopathy. The neuroradiologist interpreted the myelogram as in keeping with extramedullary compression secondary to multiple-level spondylosis, falsely suggesting an intramedullary mass lesion.

On June 7, 1974, a laminectomy from $\mathrm{C} 2$ through $\mathrm{C} 7$ inclusive, was

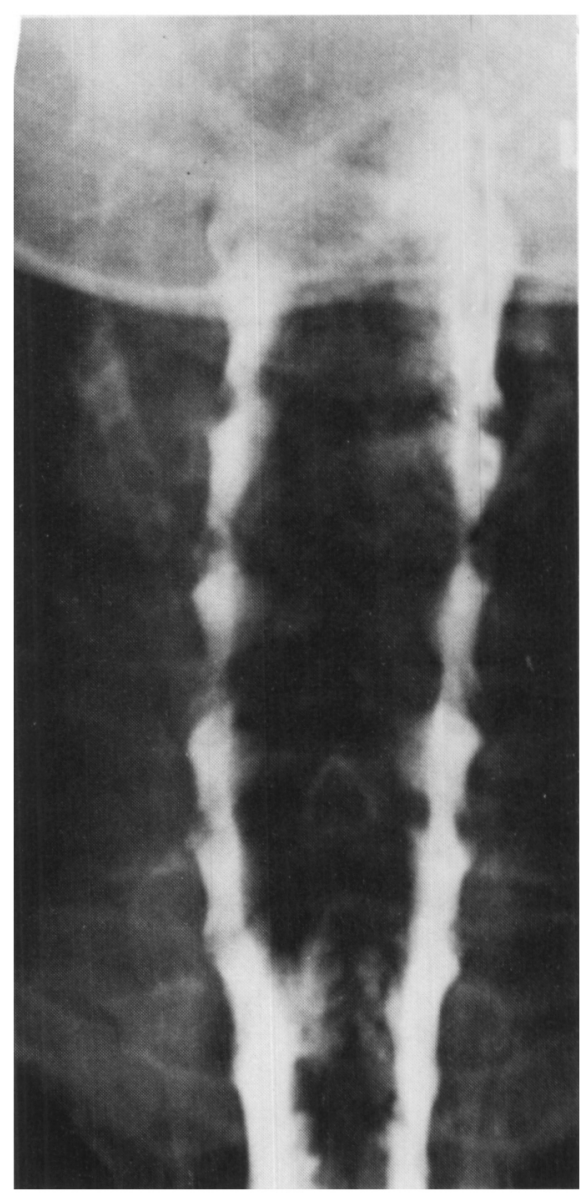

Figure 1-The A-P film of the cervica! myelogram showing symmetrical expansion of the cord from $C_{2}$ to $C_{7}$. 


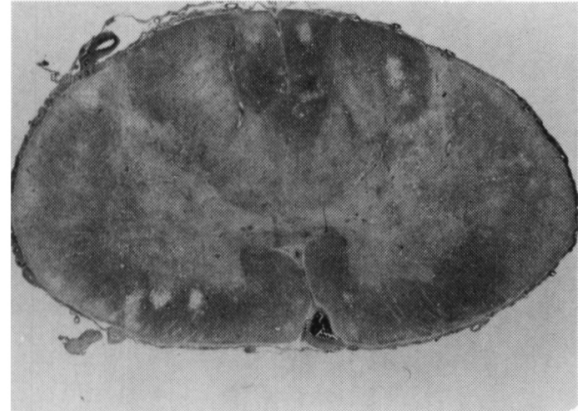

Figure 2-A myelin-stained section from the $\mathrm{C}_{3}$ level of the cord showing multiple patchy areas of demyelination and necrosis. (Kluver-Barrera, 10x).

performed. The dural sac appeared modestly compressed. The dura was opened and the cord was inspected. Nothing was seen to suggest either a syrinx or a tumor but a remarkable "chalky white" paleness of the cord was noted.

The post-operative course was uneventful until the fifth day, when the patient complained of increasing weakness again, although this could not be confirmed on examination. On the eighth post-operative day she worsened markedly. Examination revealed an almost total loss of power in the legs, and marked distal weakness of the arms and hands. Breathing was regular and unlabored, however. The anal sphincter was lax. There was a loss of pinprick sensation at $\mathrm{C} 2$, and from $\mathrm{C} 6$ to $\mathrm{T} 1$ on the right. Other sensory modalities were normal, and reflex examination was unchanged.

Such a fluctuating course developing five days following operation was difficult to explain and seemed inconsistent with either cord compression from a post-operative hematoma or cord infarction. Repeat myelography revealed a complete block at $\mathrm{T} 1 / \mathrm{T} 2$.

On June 15, 1974, following the myelogram, the previous operative site was re-opened, and the laminectomy was extended to include $\mathrm{Tl}$ and T2. No hematoma was found. The dural sac was opened. The subarachnoid space was large, and the remarkable "chalky white" appearance of the cord was noted again. We were forced to the conclusion that the myelographic block had been spurious, secondary to a marked angulation of the spine at the cervico-thoracic junction. We suspected also that the cord was undergoing progressive infarction, but were at a loss to explain the basis for this.

Post-operatively the patient developed a progressive flaccid quadriplegia with an incomplete sensory loss, and died of respiratory failure on July 4, 1974.

The autopsy was performed four and a half hours after death. Gross examination of the viscera and the brain revealed no abnormalities. The only microscopic abnormality in the general autopsy was minimal bronchopneumonia. The vessels were free of significant atheroma and showed no evidence of inflammation. Sections of the brain and spinal cord were stained with one or more of the following: haematoxylin and eosin, Kluver-Barrera, Woelcke, Bodian, reticulin, periodic acidSchiff, Warthin-Starry, Congo red, Martius Scarlet Blue, P.T.A.H. Microscopic examination of the brain was normal.

The spinal cord was removed posteriorly. There was minimal spondylosis. The cervical spinal

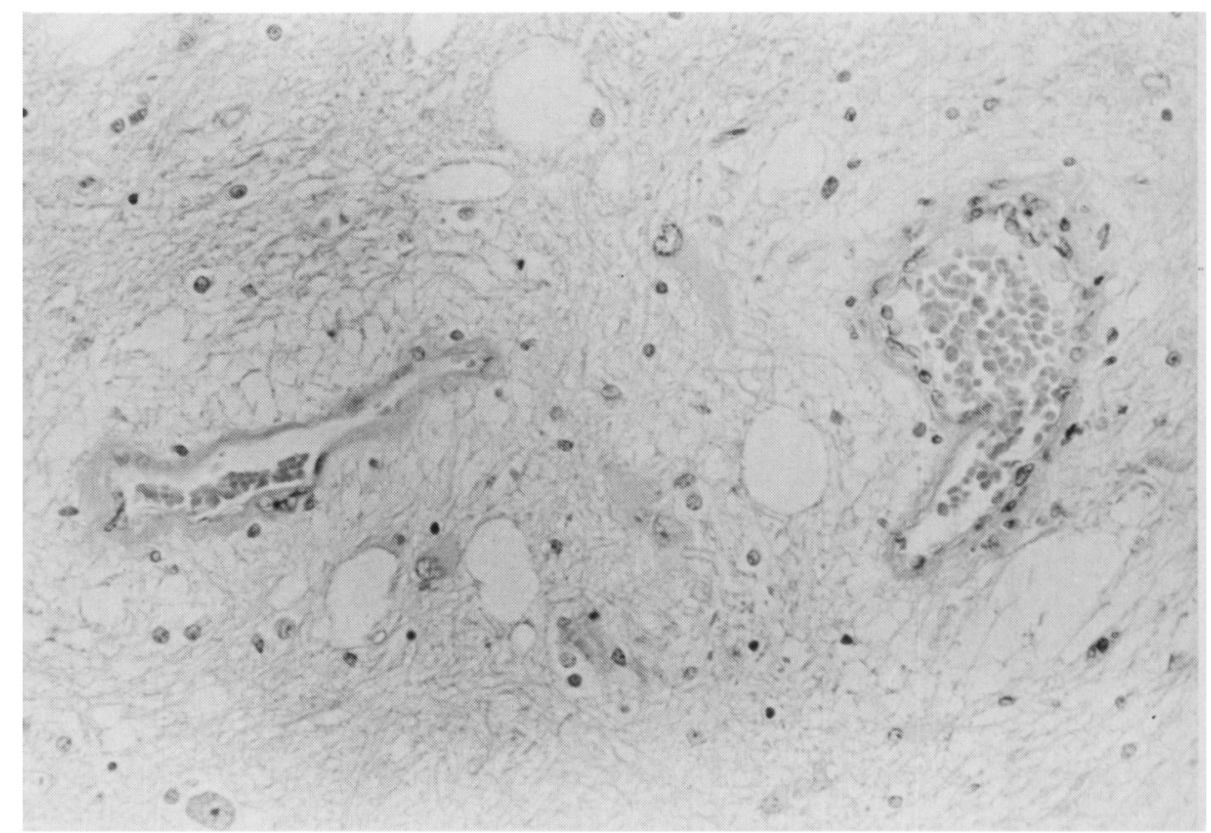

Figure $3 a-A$ section from the anterior horn at the $C_{2}$ level showing hypertrophied astrocytes, rarefied neuropile and loss of neurons. The vessel on the left has a fibrous wall while that on the right has large vesicular endothelial cell nuclei. (Hematoxylin and Eosin, 370x). cord appeared pale and broader than usual.

Myelin-stained sections of the cord (Figure 2) from $\mathrm{C}_{1}$ to $\mathrm{T}_{1}$ showed randomly-distributed patchy areas of demyelination. Sections stained with hematoxylin and eosin showed numerous areas of old (Figure 3a) and recent (Figure $3 \mathrm{~b}$ ) necrosis involving both grey and white matter. The most rostral abnormality was a focus of neuronophagia with infiltration of microglia, lymphocytes and a few polymorphs in the lower medulla adjacent to the solitary nucleus.

Striking changes were noted in the intramedullary and extramedullary arteries, arterioles and small vessels. These were both acute and chronic. Large eccentric fibrous plaques, subintimal in location, were found in many branches of the anterior spinal artery and in the posterior spinal arteries (Figure 4). The anterior spinal artery itself was patent. Some vessels, particularly those in nerve roots, appeared hyalinized (Figure 5). Others showed evidence of acute necrosis with karyorrhectic nuclear debris and inflammatory cell infiltration (Figure 6). Certain vessels had 


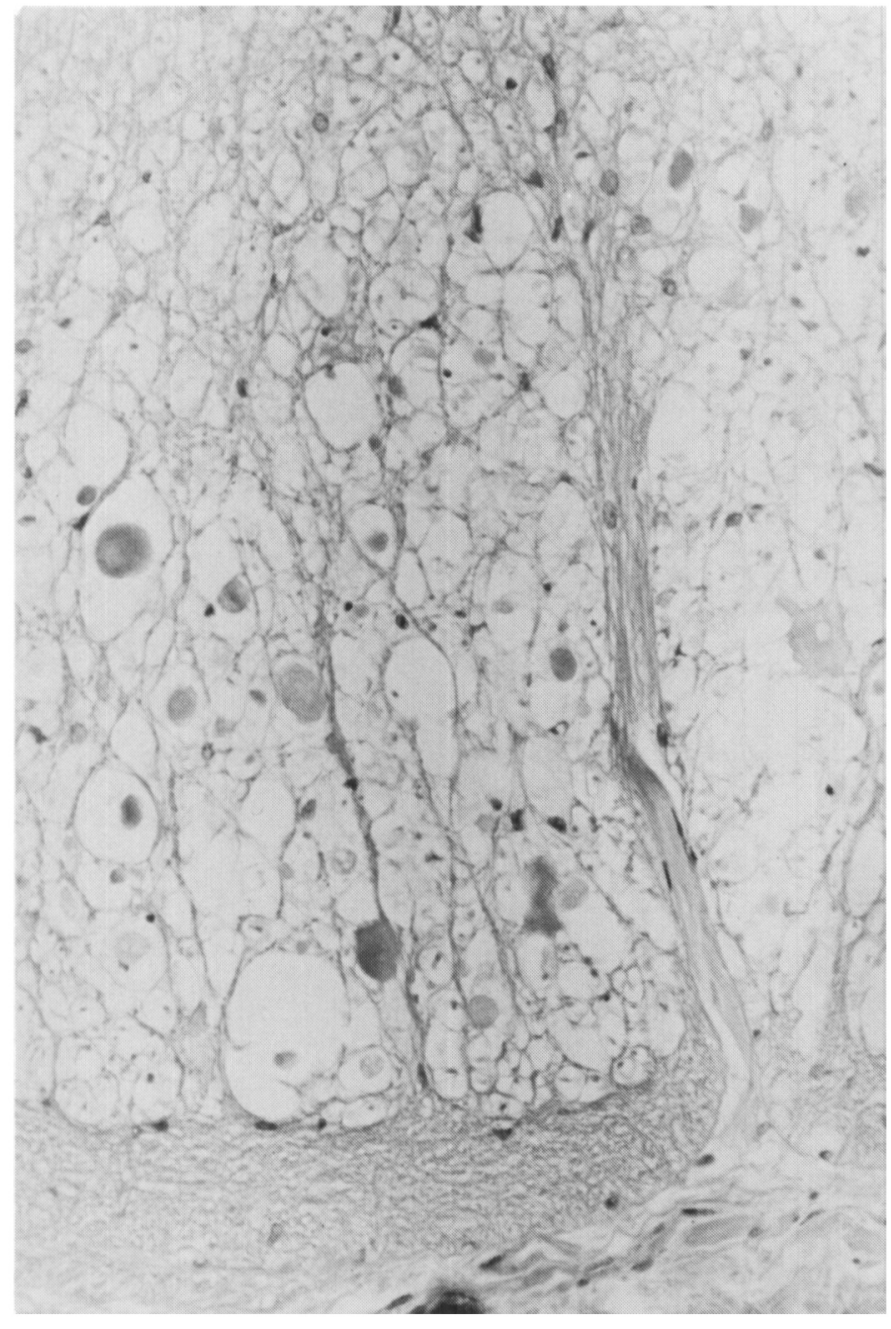

Figure $3 b-\mathrm{A}$ section from the lateral columns at the $\mathrm{C}_{6}$ level showing acutely necrotic white matter with swollen axons. (Hematoxylin and Eosin, 370x).

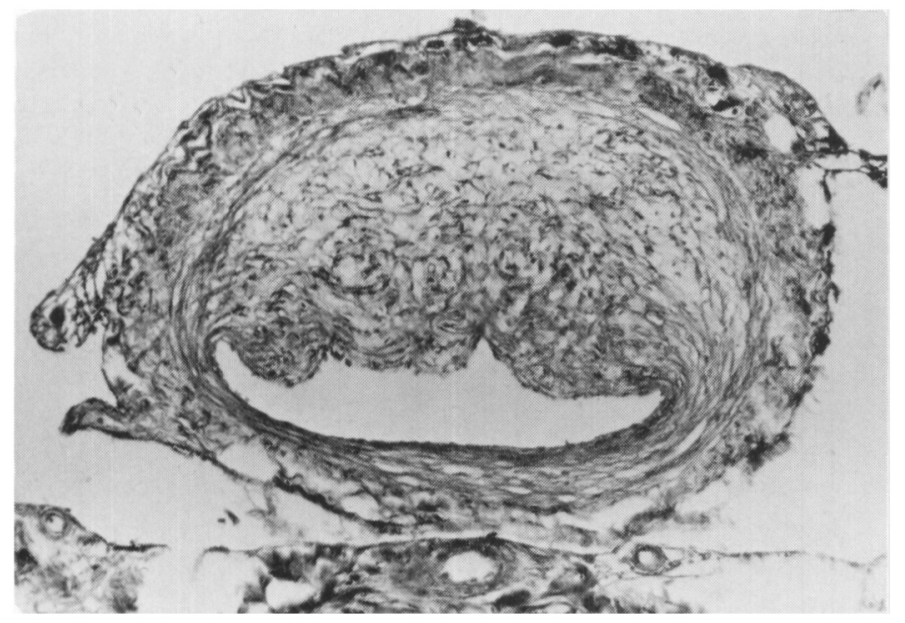

Figure 4-The right posterior spinal artery at the $C_{5}$ level showing a large eccentric edematous fibrous thickening. (Phosphotungstic acid hematoxylin, 150x).

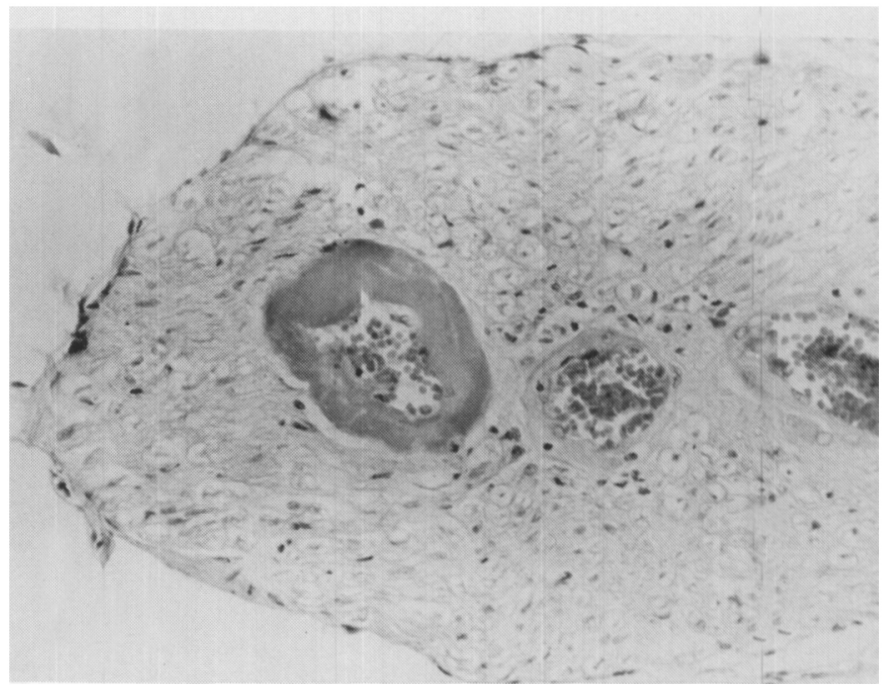

Figure 5-A hyalinzed vessel in a $\mathrm{C}_{2}$ dorsal root. Stains for amyloid gave a negative result. (Hematoxylin and Eosin. $370 \mathrm{x})$.

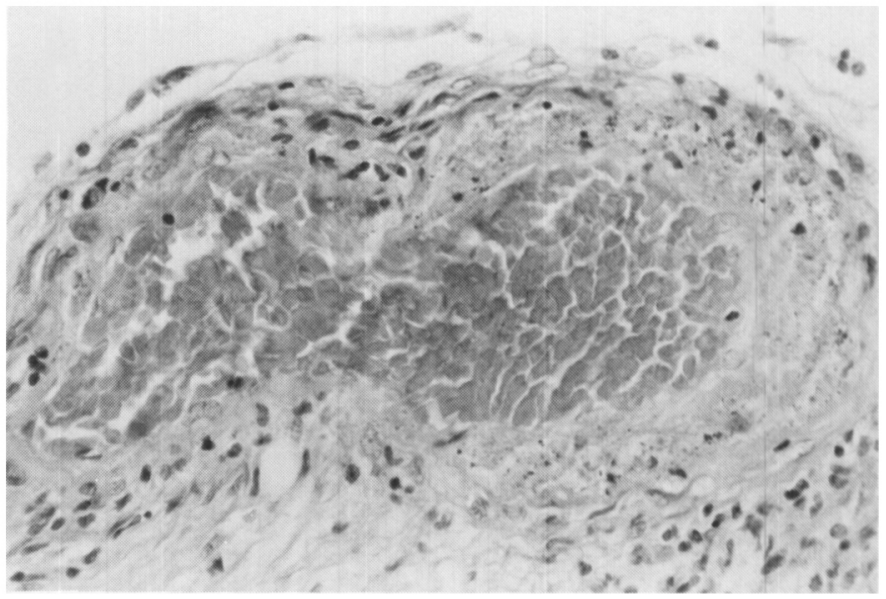

Figure 6-An acutely necrotic arteriole in a $\mathrm{C}$ s dorsal root, showing karyorrhectic nuclear debris and inflammatory cell infiltrate. (Hematoxylin and Eosin, 600x). 


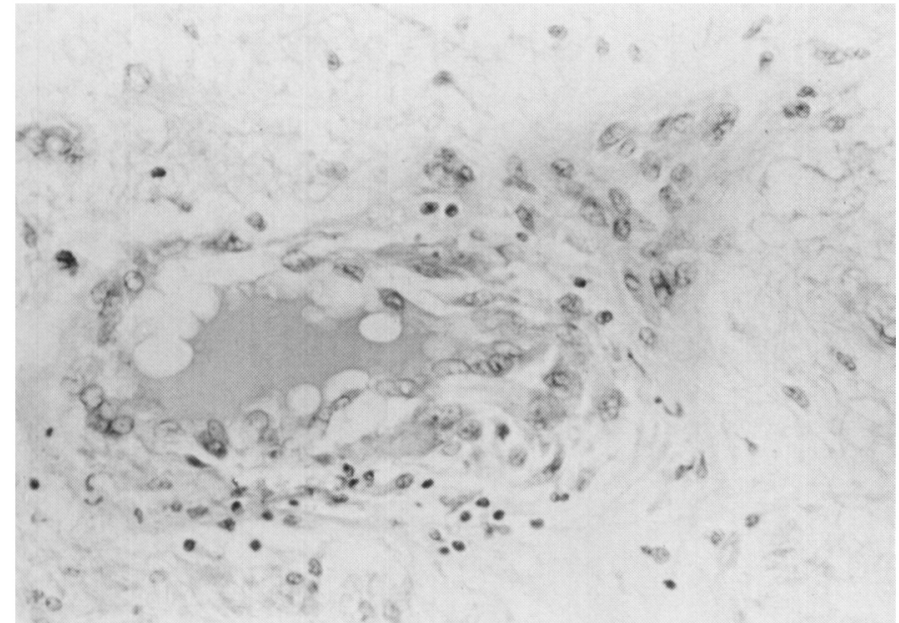

Figure $7 a-A$ small intramedullary arteriole at the $C_{2}$ level showing some disorganization of the structure of the wall with acutely swollen endothelial cells and a few inflammatory cells. (Hematoxylin and Eosin, 370x).

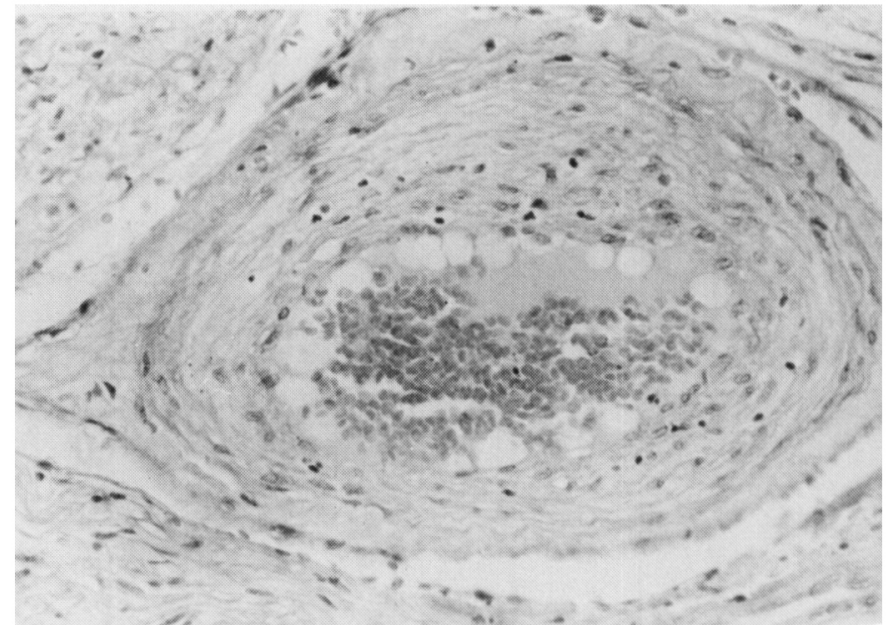

Figure $7 b-$ A large anterior spinal artery branch at the $C_{6}$ level showing mural fibrosis and inflammatory cell infiltration. (Hematoxylin and Eosin, 370x). inflammatory infiltrates but no frank necrosis (Figures $7 a$ and $b$ ). These vascular changes were confined to the spinal cord from the lower end of the medulla to the upper thoracic region.

\section{DISCUSSION}

Myelopathy due to nonhemorrhagic vascular disease is uncommon. Blackwood (1958) found no examples in 3,737 post-mortem examinations from 1909-1958 at The National Hospital, Queen Square, London. Vascular myelopathy is most frequently secondary to atheroma, particularly with involvement of, or occlusion of, the anterior spinal artery. Jellinger and Neumayer (1962) reported 21 cases of myelopathy attributed to the severe aortic atheroma found at autopsy. The current case had neither anterior spinal artery occlusion nor significant aortic atheroma.

Cervical spondylosis may produce cord infarction via secondary vascular involvement due to anterior spinal artery compression by spondylotic bars or to radicular artery compression by root sleeve fibrosis. Mair and Druckman (1953) published four cases of cervical spondylotic myelopathy, all of which had scattered gray and white matter lesions. In each case vascular changes were noted but these were confined to the small intramedullary vessels and consisted of advential, and in one case, intimal, thickening. Their published photographs show nothing approaching the severity of the lesions in the present case.

Spinal cord arteritis is a recognized complication of systemic vasculopathies. Jellinger (1967) found $2.5 \%$ of spinal cord vascular disorders in his series of 200 cases to be due to arteritis. In each case, signs of arteritis were found elsewhere in the body. A careful search of systemic and cerebral vessels in this case revealed no trace of vasculitis. Limitation of the process to the upper cord and the predominant involvement of arteries and arterioles, ruled out the distinctive myelopathy described by Foix and Alajouanine (1926).

The microscopic appearance of the lesions and their random distribution suggested that the diagnosis in this case was indeed arteritis although the process was limited. Diagnostic difficulty was experienced although the differential diagnosis included both cervical spondylotic myelopathy and an intramedullary mass. Future premortem identification of this entity will depend on either involvement of extra-spinal tissues by the disease process or the development of more sensitive diagnostic techniques.

\section{REFERENCES}

BLACKWOOD, W. (1958). Vascular disease of the spinal cord. Proceedings of the Royal Society of Medicine, 51, 543-547.

FOIX, C. and ALAJOUANINE, T. (1926). La myélite necrotique subaigue: myélite centrale angéiohypertrophique à évolution progressive paraplégie amyotrophique lentement ascendente, d'abord spasmodique, puis flasque, s'accompagnant de dissociation albumino-cytologique. Revue Neurologique, 2, 1-42.

JELLINGER, K. and NEUMAYER, E. (1962). Myelopathie progressive d'origine vasculaire: Contribution anatomo-clinique aux syndromes d'une hypovascularization chronique de la moelle. Acta Neurologica Psychiatrica (Belgium), 62, 944-956.

JELLINGER, K. (1967). Spinal cord arteriosclerosis and progressive vascular myelopathy. Journal of Neurology, Neurosurgery and Psychiatry, 30, 195-206.

MAIR, W.G.P. and DRUCKMAN, R. (1953). The pathology of spinal cord lesions and their relation to the clinical features in protusion of cervical intervertebral discs. Brain, 76, 70-91. 